\title{
Estudio crítico de la justicia penal y sistema de excepción en México
}

Critical study of the criminal justice and exception system in Mexico

Rafael Santacruz Lima ${ }^{1 *}$

Recibido: 17/09/2020 - Aceptado: 05/10/2020 - Publicado: 30/11/2020

\section{Resumen}

En el presente trabajo de investigación se realiza un estudio que parte de la idea de que el sistema de justicia penal en México ha desarrollado tres subsistemas diferentes: sistema acusatorio, medios alternos de solución de controversias y sistema de excepción. Se abordará aquí el estudio analítico del sistema penal de excepción, que de manera descriptiva ha sido incorporado en el texto constitucional y en las normas secundarias, cuyas características ponen en contradicción al sistema acusatorio, por enunciar de manera operativa e invasiva ciertas figuras jurídicas que buscan restringir y limitar derechos fundamentales de las partes en el enjuiciamiento criminal, generando con ello una serie de cuestionamientos que ponen en evidencia que la justicia penal en México no es del todo garantista. Por lo tanto, siguiendo los postulados de los sistemas democráticos de otorgar un máximo de seguirdad jurídica en el proceso penal, podemos establecer que el sistema penal de excepción está lejos de ser un sistema que vaya de la mano con el Estado constitucional; por el contrario, con sus características, elementos y funciones se asemeja más al aspecto operativo de un Estado autoritario e inquisitivo.

Palabras clave: crítica, sistema, excepción, justicia penal.

\footnotetext{
${ }^{1}$ Doctor en derecho, profesor-investigador de tiempo completo en la Facultad de Derecho de la Universidad Autónoma del Estado de México (UAEMex). Miembro del Sistema Nacional de Investigadores SNI-Conacyt (Nivel 1). Correo electrónico: rsantacruzl@uaemex.mx.
} 


\begin{abstract}
This research work seeks to carry out a study based on the idea that the criminal justice system in Mexico has developed three different systems in criminal justice, an accusatory system, alternative means of dispute resolution and an exception system. That is why it is worth studying and addressing one of the previous classifications presented by criminal justice in Mexico, the exceptional criminal system, which has been descriptively incorporated into the constitutional text, and secondary norms, whose characteristics put into contradiction to the accusatory system, for enunciating in an operative and invasive way certain legal figures that seek to restrict and limit the fundamental rights of the parties in the criminal prosecution, thereby generating a series of questions that show that criminal justice in Mexico is not of the all guarantor. Therefore, and following the postulates of democratic systems, of granting a maximum of legal security in the criminal process, we can establish that the exceptional criminal system is far from being a system that goes hand in hand with the Constitutional State, for on the contrary, with its characteristics, elements and functions, it is more similar to the operational aspect of an authoritarian and inquisitive state.
\end{abstract}

Keywords: Criticism, system, exception, criminal justice.

\title{
1. Introducción
}

El 18 de junio de 2008 se dio la reforma en materia de justicia penal y seguridad pública en México, y se estableció todo un sistema procesal penal moderno, en el que la justicia penal desarrolla un rostro humano, denominado acusatorio, con tendencia adversarial. La reforma de 2008 establece una política de Estado en la solución del conflicto generado por el delito, y estipula subsistemas alternativos de justicia; uno de ellos, el sistema penal de excepción (Santacruz, 2015).

En ese tenor de ideas, la participación del Estado, y su intervención en la justicia penal a partir de 2008 se da a través de una ligera alteración de las fuentes de legitimación, que consiste en la asunción de la emergencia o excepción, como justificación política del cambio de paradigma o, si se prefiere, del cambio de las reglas del ius puniendi mexicano. Las reglas, a las que me quiero referir, son las del sistema de excepción, establecidas en la constitución de manera invasora, en especial cuando se trata de delincuencia organizada o delitos graves, que denotan una clara contraposición a los principios y garantías procesales del sistema penal acusatorio (Santacruz, 2015).

En tal sentido, puedo afirmar que la legitimación del sistema penal de excepción se basa más en una razón de estado, o política, que en una razón jurídica o argumentativa, y por ello me surge la siguiente pregunta de investigación: ¿existe en la justicia penal en México un sistema penal de excepción que, paralelo al sistema penal acusatorio, se aplica con el objetivo de buscar el orden social y la seguridad pública de los ciudadanos, pero que en su ejecución genera una vulneración y restricción de derechos fundamentales de la población? 


\section{Razón de Estado o monopolio legítimo de la fuerza institucional}

El gran politólogo alemán Max Weber (1994) no concibe al Estado como una simple organización política depositaria de fuerza y coacción. Los ciudadanos obedecen las órdenes y normas del Estado no solo por miedo al castigo o posibles sanciones jurídicas o administrativas, sino porque lo consideran una autoridad legítima. Se establece que la autoridad requiere de un nivel considerable de obediencia voluntaria, por este motivo toda autoridad se reviste de este apoyo o sustento de legitimidad. Por lo tanto, Weber estableció la clasificación de tres formas históricas de poder político y legitimidad del poder, aunque en la realidad empírica se dan como formas impuras y mezcladas de poder político (Weber, 1994)

Podemos describir las tres formas identificadas por Weber así. La primera consiste en la legitimidad tradicional basada en la tradición, la costumbre, la creencia en las instituciones y el reconocimiento de las personas que la representan, se fundamenta en un tipo de poder legitimado por la continuación y ampliación de la tradición. Una autoridad arbitraria y tiránica podría basar su legitimidad en este modo tradicional de poder político; por mucho tiempo ha sido ejercida por los patriarcas (Weber, 1994) La segunda es la legitimidad carismática, según la cual una persona individual es reconocida como líder y jefe por sus cualidades ejemplares, acciones, heroísmo (carisma). La autoridad carismática fue ejercida por los profetas en la larga historia del pueblo de Israel, pero también por los jefes guerreros elegidos o gobernantes plebiscitarios. En este sentido, podemos considerar a Adolf Hitler como el prototipo de líder carismático secular que apareció en la escena política de 1930 y llevó a Europa hacia el desastre de la Segunda Guerra Mundial (Weber, 1994). a tercera forma es la legitimidad legal-racional (democrática) basada en un conjunto de leyes que configuran la legalidad establecida (constitución) y que dan poder y autoridad a los gobiernos nombrados conforme a un procedimiento democrático.

Entender la diferencia entre los distintos modelos del poder político es el punto de partida para estudiar y analizar las características de los tipos de autoridad, y para mostrar que si bien el papel de los dos primeros tipos de legitimidad (carismática y tradicional) ha sido muy importante en la historia, se relaciona con modelos de poder político muy inestables que tienden a perder credibilidad, mientras que la tercera forma de legitimidad (legal y racional) tiende más a la estabilidad institucional y política y se impone y extiende como un modelo de organización política en Occidente (Weber, 1989).

Con el transcurso de los años se han estudiado dos vertientes del derecho muy importantes: el positivismo, por un lado, y, por el otro, el realismo jurídico (Díaz, 1984); vertiente, esta última, según la cual la subordinación a las normas jurídicas se deriva de los instrumentos que fuerzan a cumplirlas. Por lo tanto, la responsabilidad política de acatamiento a las leyes es incondicional y absoluta, mientras que para una postura democrática la obligación de cumplir con las leyes se dará por consentimiento libre y voluntario de los ciudadanos, a través de los procedimientos formales (Aguilera, 2015)

En tal sentido, la responsabilidad política es relativa, pues depende del respeto al conjunto de principios y derechos fundamentales de los ciudadanos (Aguilera, 2015) 
a responsabilidad política, en este caso, es fundamental y transcendental, por ello la forma legal de autoridad se convierte en la forma normal y legítima en la que actúa el Estado en Occidente. En este sentido, es importante que la ley la administré un personal profesional que tenga experiencia en la aplicación racional de medios para lograr fines. La burocracia se convierte, según Weber, en la forma concreta de todo tipo de ideal racional-legal de autoridad legitimada que aparece en el Occidente.

Por lo tanto, la razón del Estado consiste en un conjunto de técnicas cuyo objetivo es la conservación política, la conservación de la autoridad y la producción de la disciplina; asegurar la obediencia (Maresca, 2005), el respeto de la teología política. La cultura de la razón de Estado es anterior teóricamente a la cultura del leviatán (o del contrato social). La razón del Estado no entiende de consenso democrático o derechos fundamentales, ni de contrato social, sino del uso de la fuerza para implantar un orden.

Esto me lleva a establecer que con la razón de Estado se pone en marcha una retórica y práctica de la "defensa de la nación" y la "protección del Estado". Asegurar una tranquilidad institucional, y no la desvinculación y desintegración de la sociedad, aun generando la desconfianza pública de un estrato de la población que día con día se ve cada vez menos beneficiada por los mecanismos de protección y nexos jurídicos y políticos que deberían tener (Bergman, 2009)

Los efectos que puede llegar a ocasionar esta deslegitimación social, unido a la falta de legitimidad de las instituciones públicas (Althusser, 1974) formales integrantes del Estado son más destructivos e insidiosos que los que cualquier "delito" pueda ocasionar al mismo Estado. La derogación del derecho, o de los derechos si se prefiere, es el núcleo esencial de la doctrina de la razón de Estado, sencillamente porque revela su verdadera función, que no es otra que la de habilitar a los gobernantes como criminales irresponsables (Maresca, 2005)

Así las cosas, en los Estados modernos, el recurso público de la seguridad llega a ser un objeto significativo (en algunos casos incluso el principal) de intercambio político entre electores y electos, entre opinión pública y sistema de la política. Y en esto quizás es posible asimilar un nuevo modelo de democratización de la política, bien sea en el sentido nuevo ofrecido por la democracia de opinión, como bien lo sugieren.

Por ello, uno de los grandes problemas que se enfrentan es la inflación del sistema penal, porque comienza a ser un elemento que pone en jaque la representación y legitimidad del Estado constitucional. En la democracia la mayoría de razón, la opinión pública, pone en evidencia la interpretación emocional del sujeto bajo sus más elementales emociones: miedo y rencor. De ahí que la forma de legitimación, por medio del discurso político, aspire a buscar una coherencia sobre las emociones, de las cuales se puede percibir el sistema de la coacción a través de la realidad y de los sentidos.

Así las cosas, gran parte de las reformas de la justicia penal en México buscan tener una razón de Estado y no una razón jurídica, porque las reformas son tomadas como respuestas a la inquietud social de seguridad. Por ello, y para no generalizar, en el aspecto operativo de la justicia penal, esas formas de razón de Estado, que no protegen 
y que vulneran derechos humanos, las puedo denominar, desde esta perspectiva, sistema penal de excepción.

\section{El sistema penal de excepción}

La interpretación de la excepción establece los conceptos que definen el derecho y el poder; mientras que el discurso que construye el proyecto de estado de derecho está diseñado para las nociones orientadas a controlar a los poderes a través de las normas (Santacruz, 2015). La emergencia o excepción solo es el momento que provocan ciertas situaciones críticas; es el punto de fractura antes de la bifurcación porque se presenta como un umbral de indeterminación entre democracia y absolutismo (Agamben, 2003).

Por lo tanto, las modificaciones del origen que permite desarrollar la justicia penal con un rostro humano han consistido precisamente en la incorporación de la emergencia o, mejor dicho, del sistema penal de excepción (antiterrorista, antimafia o anti-camorra) como justificación política de la ruptura o, si se prefiere, del cambio dentro del enjuiciamiento y funcionamiento del derecho penal (Ferrajoli, 2001a).

En tal sentido, la concepción de la emergencia, o denominado por un servidor como sistema penal de excepción, no es otra que la idea de la razón de Estado, si es que puede existir la razonabilidad en la voluntad que vulnere y restringe derechos, sobre la razón jurídica como criterio lingüístico del derecho y proceso penal, aunque sea en situaciones excepcionales como la creada por el terrorismo político o por otras formas de delincuencia organizada (Santacruz, 2015).

Así pues, un sistema de excepción se traduce en un principio normativo de intervención punitiva, no ya no en el plano jurídico sino inmediatamente político, no ya subordinado a principios de la justicia penal, como sistema de vínculos y de garantías, sino en plano del gobierno y las instituciones. En ese tenor de ideas, en el sistema penal de excepción, la ley suprema, en este caso la Constitución, a la que han de plegarse todas las demás, incorpora ciertas reglas que legitiman la participación de las instituciones y de sus actos (Santacruz, 2015)

El sistema de excepción suele formar, entonces, el origen de una legitimación externa de gran parte de toda práctica judicial, cuya función sea aplicar reglas ordinarias. En tal sentido, la actividad jurisdiccional, con un enfoque de excepción, resulta de gran complejidad por la importancia que tiene desarrollar sentencias que tengan un arsenal argumentativo que busque el respeto y la garantía de derechos fundamentales, toda vez que genera una confrontación política con la jurídica.

De tal manera, el derecho penal de excepción establece dos finalidades. En primer lugar, la legislación de que hace una enunciación de reglas en la Constitución y, por tanto, el cambio legal de principios; y en segundo lugar, la jurisdicción de excepción, alterada por la misma legalidad alterada. Lo anterior nos sugiere que están conectadas entre sí, e indica a distintos niveles una crisis del derecho penal, tal y como resulta de la creciente contradicción entre un deber ser normativo y el ser efectivo (Santacruz, 2015), 
La represión de la delincuencia organizada ha requerido en los años pasados procesos difíciles, en los que los actos autoritarios eran mayores que en los ordinarios, abriéndose la puerta además a las injusticias involuntarias. De tal manera que una regulación dentro de la Constitución y en las normas secundarias hace que se legitimen ciertas injusticias.

Por lo tanto, existen ciertos elementos del derecho penal de excepción, como por ejemplo la inflación legislativa penal, los procesos en exceso (Santacruz, 2015) la apertura de macro-investigaciones contra centenares de imputados, mediante redadas masivas basadas en frágiles indicios como actos de instrucción iniciales y prejudiciales, que han causado una estigmatización muy fuerte y discriminatoria por parte del ius puniendi (Zaffaroni, 2007)

Así, podemos decir que el derecho penal moderno establece el resurgimiento del punitivismo, cuya característica se asemeja al derecho penal del enemigo (Jakobs y Meliá 2003). Por ello, el sistema penal de excepción solo puede ser concebido como instrumento para atacar situaciones extremas o de conflicto, que pongan en jaque el orden social de todo Estado, cuyas características deben se claramente identificadas, como por ejemplo: "El sistema penal adelanta la punibilidad sobre un hecho futuro, en segundo lugar, las penas son desproporcionalmente altas. En tercer lugar, determinadas garantías procesales son relativizadas e incluso suprimidas" (Jakobs y Meliá 2003, p. 21).

Así las cosas, al verse afectados los derechos de los ciudadanos, el estado a través del sistema penal de excepción se faculta para establecer hasta qué medida será necesario limitar o restringir ciertos derechos, para ejercer el poder del Estado. De este modo, el Estado constitucional de derecho pierde su funcionamiento, toda vez que el poder punitivo del Estado da un trato que no se corresponde con el respeto a los derechos humanos, sino que genera una clasificación discriminatoria, denominando a los sujetos entes peligrosos.

Por lo tanto, la ley del derecho penal del enemigo es la excepción en los Estados de derecho, porque designa casos de especial peligrosidad en los que la seguridad pierde cierta legitimidad en la vigencia de la norma, esto es, la seguridad se ve amenazada al igual que la legitimidad de las normas, esto es, los denominados entes peligrosos ponen en riesgo el ordenamiento jurídico, generando un clima de inseguridad ante los demás ciudadanos y para el Estado (Polainos-Orts, 2008). Si ciertas normas se refieren estrictamente a esos supuestos de peligrosidad, el sistema de excepción debe ser visto y asumido como un mecanismo para el mantenimiento de la seguridad pública y la confianza de los ciudadanos, siempre que dicho mecanismo no implique que el orden social y la seguridad pública van a estar por encima de los derechos humanos, pues se debilitaría el Estado de derecho.

En esa idea, si el sujeto no cumple con lo establecido por el derecho penal, especialmente por la norma jurídica, entonces se despersonaliza parcialmente, siendo tratado por el ordenamiento jurídico como un enemigo y no como un ciudadano. Por lo tanto, se interpreta como riesgosa su falta de subordinación, es decir, como un peligro para la garantía mínima de respeto de la estructura social y de la norma. 
Se debe llamar a lo anteriormente descrito sistema penal de excepción, un sistema penal suigéneris por la forma como son vistos los derechos humanos, porque este se dirige contra los ciudadanos que alteran el orden legal con actos que van contra de las reglas establecidas por el Estado, por lo que deben ser sancionados de manera enérgica, pues lo que está en juego es la seguridad y el orden social (Santacruz, 2015).

\section{Elementos de la excepción en la justicia penal en México}

En México, hace poco más de once años ${ }^{2}$ se generaron cambios legislativos en materia de justicia penal y seguridad pública. Entre los más importantes estuvo una reforma constitucional, un Código Nacional de Procedimientos Penales. Hubo también capacitación del personal operativo, y generación de la infraestructura necesaria para llevar a cabo la implementación de un paradigma de justicia penal. Asimismo, surgió el diseño de un sistema de medidas alternativas al juicio, cuya responsabilidad recae en los jueces de garantía que lo hacen funcionar (Carbonell y Ochoa, 2008).

Estudiar, aunque sea una pequeña parte de todos esos asuntos, rebasa por mucho el objetivo del presente artículo, por lo que me limitaré a realizar algunas reflexiones y críticas al sistema de excepción penal, en el plano más general, en el de aquellos supuestos que son invasores a los derechos humanos y garantías de los sujetos que intervienen en el proceso penal, y en especial a ciertas figuras que se desarrollan en la Constitución.

En tal sentido, hay que partir de que el sistema penal de excepción en México debe reunir ciertos elementos, y hay que agregar que todo proceso penal requiere de un mejor derecho penal sustantivo, ya que solo con este el proceso puede obtener buenos resultados. Como lo señala Ferrajoli (2001b), las garantías penales pueden, a su vez, considerarse necesarias para garantizar juicios que no sean arbitrarios; tanto las garantías penales como las procesales valen no solo por sí mismas, sino también, unas y otras, como garantía recíproca de su efectividad. Por lo tanto, la correcta comprensión del proceso penal no será satisfactoria sin un derecho penal sustantivo que se construya bajo esquemas de racionalidad, proporcionalidad y uso limitado del ius puniendi del Estado (Ferrajoli, 2001b).

Por ello, es posible concluir que la base fundamental de la reforma de justicia penal realizada hace más de una década debió ser la incorporación de garantías tendientes a proteger los derechos de todos los sujetos en el escenario penal: víctimas, ofendidos, inculpados, acusados, sentenciados, Ministerio Público, jueces, y abogados (Carbonell y Ochoa, 2008).

El conjunto de tales garantías es de vital importancia en el enjuiciamiento, por ello debemos entender su aplicación (Carbonell y Ochoa, 2008, p. 83). Las garantías que buscan reconocer los derechos de los actores en el proceso penal deben tener presente que el desarrollo de cada una de las etapas en el enjuiciamiento se ha de cumplir de

\footnotetext{
${ }^{2}$ No cabe duda de que, desde la aprobación de las reformas y adiciones constitucionales publicadas en el DOF el 18 de junio del año 2008, se ha desatado a lo largo y ancho de México un sinnúmero de acciones y políticas públicas encaminadas a dar cauce al dominado nuevo sistema de justicia penal.
} 
conformidad con los principios constitucionales y con apego al debido proceso penal (Santacruz, 2015).

Así, el derecho penal, en el ámbito jurisdiccional, se debe realizar respetando ciertas precondiciones judiciales que permitirán tener el escenario correcto para el desarrollo del juicio. Así las cosas, debemos buscar que siempre exista en todo juicio la independencia, la imparcialidad y la objetividad de los jueces, y la separación entre acusación y juez (Carbonel, 2008). Por ello, el juicio penal debe contar con atribuciones a desarrollar en el procedimiento, y que aseguren una serie de principios, o cargas axiológicas, que le den contendido a la norma jurídica (Carbonel, 2008).

En tal sentido, y conociendo las anteriores garantías o precondiciones, se puede afirmar que, de forma paralela al llamado sistema penal acusatorio, y en contraposición a la Constitución Política de los Estados Unidos Mexicanos, existe, bien definido, lo que he denominado un sistema penal de excepción, que tiene la finalidad de reducir garantías y potencializar la intervención del Estado en el proceso penal; sistema contradictorio a todo sistema penal garantista.

Así las cosas, el sistema penal de excepción en México busca, a través de la actividad legislativa, estigmatizar conductas de riesgo con penas muy altas y de corte antidemocrático. En la Constitución, hace más de diez años, con la reforma de justicia penal y seguridad pública, podemos estudiar y analizar reglas punitivas -lo que considero grave, ya que toda Constitución debe enunciar principios, no reglas- destinadas a la solución del problema de seguridad pública que vive el país. En este estudio de las reglas se encuentra la reducción de garantías en el proceso penal, la restricción de derechos al imputado, que abre la posibilidad de vulneración de derechos humanos.

Para ir desentrañando los elementos del sistema penal de excepción, en la justicia penal en México, analizaré los siguientes preceptos establecidos en el texto constitucional, incorporados el 18 de junio de 2008, y subsecuentes a dicha reforma:

Párrafo $9^{\circ}$ del artículo 16. "Por delincuencia organizada se entiende una organización de hecho de tres o más personas, para cometer delitos en forma permanente o reiterada, en los términos de la ley de la materia" (Cámara de Diputados del H. Congreso de la Unión, 2019). Una clara descripción de un tipo penal, misma que es exclusiva de los códigos penales o normas secundarias, no de las constituciones.

\section{Apartado B, Frac. V del artículo 20.}

Será juzgado en audiencia pública por un juez o tribunal. La publicidad sólo podrá restringirse en los casos de excepción que determine la ley, por razones de seguridad nacional, seguridad pública, protección de las víctimas, testigos y menores, cuando se ponga en riesgo la revelación de datos legalmente protegidos, o cuando el tribunal estime que existen razones fundadas para justificarlo (Cámara de Diputados del H. Congreso de la Unión, 2019).

Por lo tanto, constitucionalmente se establecen las excepciones al principio garantista de la publicidad, al establecer que el imputado no será juzgado en audiencia pública. 


\section{Apartado B, Frac. V, segundo párrafo del artículo 20.}

En delincuencia organizada, las actuaciones realizadas en la fase de investigación podrán tener valor probatorio, cuando no puedan ser reproducidas en juicio o exista riesgo para testigos o víctimas. Lo anterior sin perjuicio del derecho del inculpado de objetarlas o impugnarlas y aportar pruebas en contra (Cámara de Diputados del H. Congreso de la Unión, 2019).

Es decir que operará la prueba anticipada, una forma diferente de ofrecer, desahogar y valorar la prueba, a la que se lleva en el sistema acusatorio, que debe ser desahogada en audiencia final del juicio.

A partir de estos preceptos, nos damos cuenta de que la reforma constitucional de 2008 no es en su generalidad garantista, es decir, que no se percibe generalizado el sistema acusatorio adversarial; por el contrario, se busca dar las herramientas jurídicas al Estado para poder intervenir en el proceso penal, por medio de reglas y estrategias que van enfocadas a la vulneración o restricción de derechos humanos.

Por lo tanto, y si seguimos los principios de todo enjuiciamiento garantista, debería realizarse el proceso penal bajo las mismas prerrogativas y garantías, es decir, las partes en el proceso penal deben contar con las mismas oportunidades para ofrecer, desahogar y contradecir las pruebas. En tal sentido, si se cumplen cabalmente estas prerrogativas, se estaría hablando de un correcto sistema penal acusatorio.

Por ello, los supuestos que he descrito y que se encuentran establecidos en la constitución no cumplen con los parámetros mínimos de un sistema acusatorio. En consecuencia, sostengo que, paralelo al sistema penal acusatorio, existe un sistema bien definido de excepción, propio de los estados autoritarios e inquisitivos, que proporciona a sus ciudadanos un mínimo de seguridad jurídica y un máximo de violencia por parte del Estado.

\section{Conclusiones}

De acuerdo con lo estudiado en el presente artículo, la razón del Estado consiste en un conjunto de técnicas cuyo objetivo es la conservación política, la conservación de la autoridad y la producción de la disciplina, el aseguramiento de la obediencia. La cultura de la razón de Estado es anterior teóricamente a la cultura del leviatán (o del contrato social). La razón del Estado no entiende de consenso democrático o derechos fundamentales, ni de contrato social, sino del uso de la fuerza para implantar un orden.

El cambio constitucional del 18 de junio de 2008 en materia de justicia penal y seguridad pública estableció un sistema penal acusatorio, pero también reglas punitivas dirigidas a combatir la inseguridad pública. Para ello, en el enjuiciamiento penal se estableció un sistema penal de excepción que minimiza las garantías del debido proceso, restringe derechos, en especial del imputado, y posibilita el acuerdo con las personas involucradas en el delito. Por lo tanto, el sistema penal de excepción es una forma 
característica que tiene el Estado de imponer su razón, por el que no se desarrolla un proceso penal garantista, sin que exista ningún discurso jurídico justificativo para ello.

De no existir un sistema garantista en su generalidad se ponen en riesgo el respeto de los derechos fundamentales de las personas que interviene en el enjuiciamiento. Por ello, propongo que, para evitar la presencia del sistema de excepción, se eliminen las reglas insertadas en la Constitución que son propias de los códigos penales, para que cobren importancia los principios del sistema acusatorio. Es decir, solo eliminando estas reglas de la Constitución se podrá aspirar, por parte del Estado, a otorgar un máximo de seguridad jurídica y un mínimo de violencia hacia sus ciudadanos.

\section{Referencias}

Aguilera, R. (2015). Criminología Política. México: Res Pública.

Agamben, G. (2003). Estado de Excepción. Buenos Aires: Adriana Hidalgo Editora.

Althusser, L. (1974). Ideología y aparatos ideológicos de Estado. Buenos Aires: Nueva Visión.

Bergman, M. (2009). Confianza y Estado de derecho. En Marcelo Roserantz Bergman (coord.), Confianza y derecho en América Latina, pp. 77 - 99. México: Fondo de Cultura Económica.

Carbonell, M. (2008). Los juicios orales en México. México: Porrúa.

Carbonell, M. y Ochoa, E. (2008). ¿Qué son y para qué sirven los juicios orales? México: Porrúa.

Díaz, E. (1984). De la maldad Estatal y la Soberanía Popular. Madrid: Editorial Debate.

Ferrajoli, L. (2001a). Derecho y Razón. Teoría del Garantismo Penal (5a ed.). Madrid: Trotta.

Ferrajoli, L. (2001b). Derechos y garantías. La ley del más débil (2ª ed.). Madrid: Trotta.

Jakobs, G. y Meliá, C. (2003). Derecho Penal del enemigo. Madrid: Civitas.

Maresca, M. (2005). Antes de leviatán, las formas políticas y la vida social en las crisis del imperio de la ley. Derecho penal del enemigo. En Guillermo Portilla Contreras (coord.), Mutaciones de leviatán legitimación de los nuevos modelos penales, pp. 87 - 118. Madrid: Universidad Internacional de Andalucía.

México. Cámara de Diputados del H. Congreso de la Unión. (2019). Constitución Política de los Estados Unidos Mexicanos. Recuperado de https://mexico.justia.com/federales/constitucion-politica-de-los-estados-unidos-mexicanos/titulo-primero/capitulo-i/

Polainos-Orts, M. (2008). El derecho penal del enemigo como garantía de la juridicidad democrática Estatal. México: Flores editores y distribuidor.

Santacruz, R. (2015). La prueba en el sistema penal de excepción. México: Porrúa-Print.

Weber, M. (1994). Economía y sociedad. México: Fondo de Cultura Económica.

Weber, M (1989). El político y el científico. Madrid: Alianza.

Zaffaroni, E. (2007). El enemigo en el Derecho Penal. México: Ediciones Coyoacán. 